\title{
A Valuable Publication
}

\author{
Seda Gasparyan \\ Yerevan State University
}

\author{
Much More than Metaphor \\ Master Tropes of Artistic Language and Imagination \\ Elzbieta Chrzanowska-Kluczewska \\ Frankfurt am Main: Peter Lang, 2013, 196 pp.
}

Prof. Dr. hab. Elzbieta Chrzanowska-Kluczewska's new book Much More than Metaphor: Master Tropes of Artistic Language and Imagination is a significant contribution to the development of the all-important sphere of literary studies at large and the study of artistic language in particular. As a result of the author's long-standing investigative experience in the field, the book demonstrates the wide scope of not only her scholarly interests but also her expert knowledge of the questions discussed.

The indubitable success of the author's logically consistent and circumstantial investigation consists in the fact that she does not confine her research to the study of "the gist of tropology" only (which is itself an enormously intricate domain of philosophical, literary, linguistic, etc. studies), but also tries to survey the behavior of the most important tropological figures in discourse viewing them as vivid means of imaginative reverberation of the objective reality and "exemplars of our imaginative conceptualization" of it.

As outlined in the introduction, in the vast field of research on poetic language the author positions herself "with our founding fathers" - Aristotle and Quintilian, then travels through Renaissance Europe to our contemporary world. Her observations throughout this long travel show, and this is of especial importance, that contemporary investigations, however novel they might be, are very often firmly rooted in the rhetorical tradition of ancient theories and approaches.

Put in poetically "metaphor is the heart of any language," and it is not a mere chance that numerous studies have been and are still being devoted to the investigation of this multidimensional trope, but what distinguishes this particular study is that it focuses much on the interdisciplinary nature of figuration in general and metaphorization in particular. Proceeding from R. W. Emerson's fundamental idea that "thought is prior to the form" the author believes in the priority of the conceptual realization of tropological figures in mind and only after that their expression in language. Metaphor and the other major figures of speech are not only meant to decorate speech, make it more vivid and elevated, but also introduce completely fresh ideas into the utterance and enhance the reader's perception of the surrounding world. 
The book consists of four chapters.

Chapter I of the volume (From Microtropes, through macrotropes, to mega- and metatropes of artistic language and conceptualization) presents the author's definition of tropes as "a class within the broad family of figures" (p. 19), "involving changes and transfers of meaning" between lexemes and lexical sequences (p. 21). The discussion of the notions of figure and trope as described by Aristotle, Quintilian, Auerbach, Valery, Burke, Rosiek, Riddel, Cohen, White serves as a firm and reliable ground for the author's detailed and scrupulous investigation of "big" and "small" functional varieties of tropes (microtropes, macrotropes, megatropes) and the subgroup of large figures (metatropes in the author's terms).

Accepting the traditionally established idea of tropes as based on transferred meaning and actualized not only in words, but also phrases, sentences and texts, the author studies metaphor, metonymy, synecdoche and irony as models of excellence among tropes, defines them as master tropes (in K. Burke's terms) and makes a successful attempt to bring out their metatextual potential in discourse.

In Chapter 2 (The Vichian tropological tetrad and its contemporary variants) the author's choice and scrupulous survey of the four powerful tools of creativity mentioned above, actually from the list of tropes elaborated by Quintilian, is utterly justified, for they are, indeed, master tropes that gained prominence already in antiquity and continue stirring the interest and enthusiasm of researchers up to this day. In this part of the book by Prof. hab. Chrzanowska-Kluczewska these tropes are analysed from the point of view of Giambattista Vico's interpretations which have played an indispensable role in the development of the theory of tropological devices. It is from the statements and principles elaborated by G.Vico, as well as S.T. Coleridge that A.A. Richards proceeds when he associates the functioning of language in the society with metaphor and persistently develops the idea that metaphoricity of language derives from the metaphoricity of thought. Thus, echoing back to the Aristotelian estimation of the device, the author proposes that metaphor is given the place of pride among other major tropes, and her proposition sounds quite convincing as it is through metaphor that the infinite possibilities of imagination are revealed. Moreover, the power of the author's investigative mind and her insight into poetic language stimulate her conviction of going beyond the Vichian tetrad and adding other tropes to it. She emphasizes the idea that they are endowed with "a generality of patterning that makes them fit candidates for tropological universals" (p. 87).

The chapter is rich in background theoretical considerations and vivid illustrations.

Chapter 3 (Beyond the Vichian circle) touches upon the issues of the usage of the tetrad in other fields of study, such as different areas of human conceptualization, mental activity and expression (p. 89). Particularly, Sigmund Freud's language of dreams related to the Vichian master tropes, Lacan's figures of the unconscious and Levi-Strauss" tropes of the "savage" mind are considered. Among extended master 
tropes simile-comparison, antitheses, catachresis, euphemia (understatement), suppression, hyperbole (exaggeration) are thoroughly studied and illustrated. One of the important ideas emphasized in the book is the question of an additional quality of tropes, namely their ludic function that, as the author believes, ought, by no means, to be forgotten or disregarded. Indeed, as justly noted by the author, "all tropes are instruments of play/game within the vast extenses of figurative space, in which the author, the text and the receiver are brought together." Being freely created in the text under the influence of the writer's rational, emotional and aesthetic experience all the tropes have this ludic element in their depth and require an adequate echo on the part of the reader to be understood adequately.

In Chapter 4 (Tropological space and figurative worlds) figurative worlds, perspectivization and spatial transformations within tropological space are discussed. Tropological space, figurative and rhetorical in nature, is viewed as subpart of logical, textual/discourse and artistic space. Through metaphoricity logical space can be expanded towards alien, unknown spheres of cognition. The scholar's approach here to treat metaphor as an umbrella term for all kinds of tropes is grounded and justified (136), particularly that the recent analyses have convincingly demonstrated that figuration is a pervasive phenomenon. In fact, tropological space can also be attached to non-literary texts and discourses (textual/discourse space), and this fact, as investigations have shown, finds corroboration in discourse studies related to the language of politics, science, medicine, law, education and the media (p. 138). However, basing the illucidation of the conception of artistic space on the studies of the Tartu and Moscow schools of Semiotics (Lotman, Uspiensky, Minc, Toporov), the author views tropological space as a chunk of literary/fictional/artistic space and envisages artistic space as an imaginative world called to life by poetic language. Imagery and creative metaphors reign supreme here. Single-world and double-world approaches (referring to metaphorical concepts in fictional worlds) are also argued in this chapter to state that metaphors, being both semantic and conceptual constructs require some metaphysical extension and are projected onto a deviant world, which in its structure encompasses impossibilia and logical contradiction and that even "nonwordly texts are capable of carrying within their space very small worlds created by single tropes or their local clusters, most typically metaphor" (p. 154).

Thus, the present scholarly investigation of metaphor, based on firm theoretical background, adheres to the multi-tropical approach to human discourse and will be of utmost importance to both language and literature theorists. It is a valuable addition to the study of metaphor, metaphoricity, tropology and artistic language at large.

This monograph by Prof., Dr. hab. Elzbieta Chrzanowska-Kluczewska is by right "much more than metaphor."

C 2015, SEDA GASPARYAN, Yerevan State University, Armenia 